\title{
Biomicroscopic examination of the ocular fundus with a +150 dioptre lens
}

\author{
Nicholas Blaire Lee
}

\begin{abstract}
This article describes the design of a +150 dioptre compound lens for biomicroscopic examination of the fundus. To compare the lens with other fundal examination techniques a method is described for measuring the magnification and vertical angle of view of the various examination lenses. By this method the +150 dioptre lens is shown to have an angle of view of $60^{\circ}$. This is similar to that of the indirect ophthalmoscope when used with a 20 dioptre lens which has an angle of view of $57^{\circ}$. However, the magnification of the +150 dioptre lens is greater at $\times 5 \cdot 2$ compared with $\times 3.0$ for the indirect ophthalmoscope. The practical applications of the lens are discussed. In comparison the field of view of the +78 and +90 dioptre lenses are $37^{\circ}$ and $29^{\circ}$ respectively. The +150 dioptre lens has proved a useful adjunct enabling a rapid global screening of the ocular fundus on the slit-lamp before examining any particular area of interest in more detail.
\end{abstract}

Since Helmholt $z^{1}$ first examined the fundus with a direct ophthalmoscope in 1851 there has been a great diversity of lenses and tools to examine it..$^{2-5}$ El Bayadi' first reported using a high powered convex lens, +56.8 dioptres, with the slit-lamp microscope in 1953. With the improvements in the quality of optical manufacture in the 1980s the double aspheric +90 dioptre lens has become the standard lens to conduct biomicroscopy of the fundus. The recent introduction of the +78 dioptre lens further emphasises the popularity of using a non-contact lens. The good quality stereomagnified view produced in this way is especially suited to examining the optic disc and posterior pole. This often avoids the need for a fundal contact lens examination, so reducing examination time and the patient's discomfort.

However, the +90 dioptres lens's very advantage of a magnified image limits the field of view. This may cause a more peripheral or global lesion to be overlooked. In addition when using the +90 dioptre lens media opacities can seriously reduce the retinal image quality. To overcome these difficulties many may turn to the head mounted indirect ophthalmoscope, with a wider global field of view and far less trouble from media opacities. Thus there is a need for a noncontact fundal lens which produces a much wider field of view. This can be achieved by using a higher power examination lens.

This article describes a +150 dioptre compound lens which is used with the slit-lamp in a similar fashion to the +90 dioptre lens. The field of view obtained with the +150 dioptre lens is compared with that obtained by variety of other fundal examination techniques.

\section{Lens design}

In order that light from a large field of view may pass through a single fundal examination lens it has to be large. However, the very small $(6.8$ $\mathrm{mm}$ ) radius of curvature of a +150 dioptre single lens limits its overall size. Together with the marked peripheral aberrations of such a lens, the overall useful field of view would be limited. This well known difficulty is encountered in microscope and telescope eyepieces. In these instances the problem is overcome by using two separated positive lenses, so forming the standard Huygens eyepiece. ' The field lens is placed at the focus of the main eye lens to increase the field of view but leaves the magnification unaltered. If, however, the two lenses are moved closer together the dioptric power of the combination increases, while the lens still maintains the advantages of increased field of view and reduced aberrations of the Huygens lens.

The +150 dioptre lens is thus produced by two +80 dioptre double convex $11 \mathrm{~mm}$ diameter glass lenses separated by a $5 \mathrm{~mm}$ air gap (Fig 1). The optics are in principle identical to those of the $90 \mathrm{D}$ (Fig 2). A possible disadvantage in using a combination lens is the increased amount of reflections from the optical surfaces. This is minimised by having the lenses coated with a multilayered antireflecting coat. In addition an oblique light source is used, and as a consequence no significant reflections from the optical surfaces are encountered. The overall size of this combination lens makes it pleasantly comfortable to hold and easy to handle.

The +150 dioptre lens together with the +90 and +78 dioptre lenses share the disadvantages of the inverted indirect view, and liability to fatigue the user, of a hand held lens. These lenses also share the disadvantage of having a slit

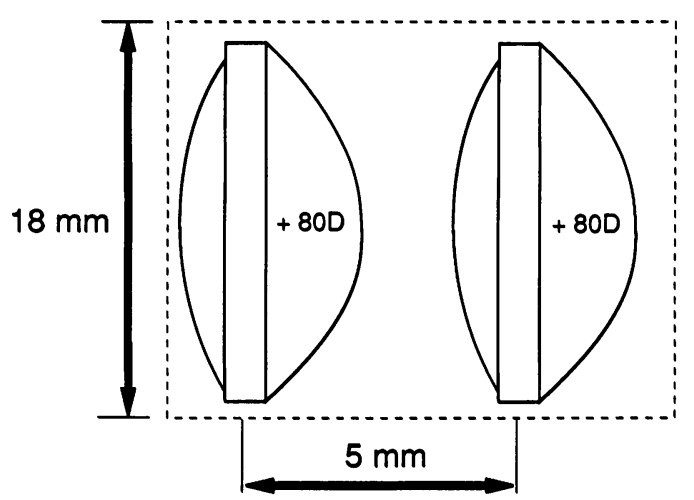

Figure 1: Optical construction of the lens. 
Figure 2: To measure the angle of view $(\theta)$ of the various examination lenses two measurements in $\mathrm{mm}$ were made: (a) the vertical size of the optic nerve image $\mathrm{O}^{\prime}$; (b) the maximum vertical size of the curved retinal image $R^{\prime}$ generated by the illumination beam.

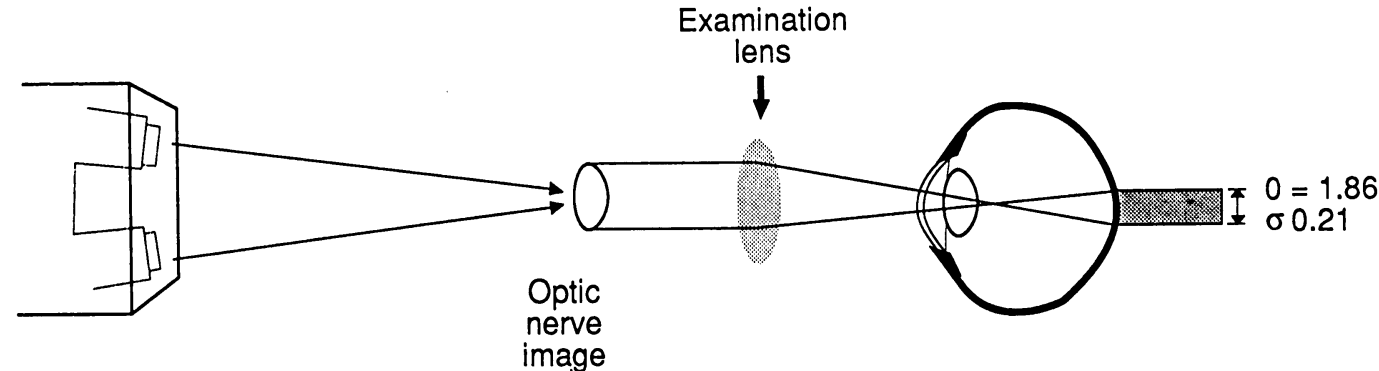

$\left(0^{\prime}\right)$

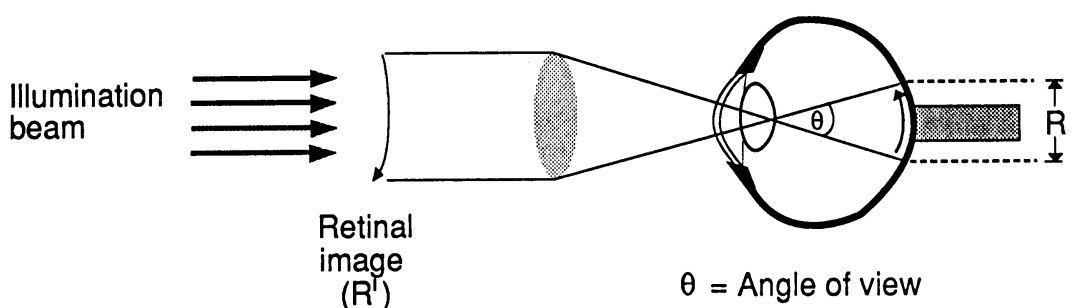

illumination rather than the $360^{\circ}$ illumination of the indirect ophthalmoscope.

\section{EVALUATION OF FIELD OF VIEW}

To avoid the complexity of using a theoretical calculation on the complex optical system created by the slit-lamp, examination lens, and the eye, a clinically based method was devised to measure the angle of view. The size of the optic disc has been studied in 200 post-mortem eyes by Straatsma $e t a l^{8}$ and found to vary within small limits. The vertical size was found to be $1.86 \mathrm{~mm}$ (SD 0.21). This vertical diameter of the optic disc was used as a scale from which the vertical angle of view could be calculated (Fig 2).

Twenty-one emmetropic patients were examined by the author. The pupils were dilated with tropicamide $1 \cdot 0 \%$ and phenylephrine $10 \%$. The fundus was examined by the following methods: slit-lamp based $+150 \mathrm{D},+90 \mathrm{D}$, $+78 \mathrm{D}$, Hruby lenses, and fundal contact lens; indirect ophthalmoscope with $+14 \mathrm{D},+20 \mathrm{D}$, +30 D, and the Hamblin 2000 direct ophthalmoscope. Measurements of the vertical size of the optic disc were made together with the maximum vertical field of view illuminated at any one moment. For the $+150,+90$, and +78 dioptre lens these measurements were made on the image formed between the lens and the slit-lamp. The scale of a $1000 \times 0.1 \mathrm{~mm}$ graticule microscope slide was superimposed on this optic disc image and the maximum diameter of the optic disc recorded.

In a similar fashion a standard millimetre ruler was used to measure the image produced between the lens and the indirect head piece. However, with the Hruby and fundal contact lenses no image is produced between the lens and the slit-lamp. Therefore the graticule scale could not be superimposed on the optic disc image. Instead a Haag-Streit slit-lamp with a scaled vertical slit-lamp illumination beam was used. The slit-lamp's inbuilt millimetre slit length scale was checked and compensated for with the graticule microscope slide. The optic disc size and maximum vertical field of view could then be measured with the illuminating beam. With the direct ophthalmoscope the number of disc diameters in the vertical field of view was estimated by observation. The ratio of the image size of the optic disc to the actual optic disc size will be the same as the maximum vertical measurement of retina in view to its actual measurement in the eye (Fig 2). Thus

$$
\text { Vertical distance of retina in view } R=\frac{R^{\prime} \times O}{O^{\prime}}
$$

As the retina and its image are both curved, the vertical measurement made represents a chord across the posterior pole of the eye. With Gullstrand's schematic eye ${ }^{910}$ with an inner equatorial diameter of $24 \cdot 1 \mathrm{~mm},{ }^{11}$ a scale drawing of the eye was made on $1 \mathrm{~mm}$ squared paper. Though the human eye is an oblate spheroid, ${ }^{12}$ the posterior pole was assumed to be spherical. The chord could then be drawn in and the angle of view $(\theta)$ could be read off with a protractor. The magnification of the image is calculated by dividing the mean optic disc image size by 1.86 (the mean vertical disc diameter) and multiplying this by the slit-lamp magnification, if appropriate.

\section{Results}

The mean and $95 \%$ confidence limits of the measurements taken are tabulated in Table I. The +150 dioptre lens was found to have the largest vertical field of view of $60^{\circ}$. This was closely followed by the indirect ophthalmoscope used with the 20 dioptre lens, with a field of view of $57^{\circ}$. The +90 dioptre lens field of view was smaller at $37^{\circ}$ and the +78 dioptre lens at $29^{\circ}$. The fundal and Hruby lenses were more prone to have their field of view limited by the patient's pupil than the others. For the fundal lens the field of view was $20^{\circ}$ and the Hruby lens $17^{\circ}$. However, the Hruby and fundal lenses produced the maximum magnification of all the lenses of $\times 11 \cdot 7$ and $\times 11 \cdot 2$. 
TABLE I Angle of view and magnification of various examination lenses

\begin{tabular}{|c|c|c|c|c|c|c|c|}
\hline Lens type & $\begin{array}{l}\text { Number of } \\
\text { observations }\end{array}$ & Disc size, $m m$ & $\begin{array}{l}95 \% \\
\text { Confidence } \\
\text { limits, } \mathrm{mm}\end{array}$ & $\begin{array}{l}\text { Illumination } \\
\text { size, } \mathrm{mm}\end{array}$ & $\begin{array}{l}\text { Overall } \\
\text { magnification }\end{array}$ & $\begin{array}{l}\text { Angle of view, } \\
\text { degrees }\end{array}$ & $\begin{array}{l}95 \% \\
\text { Confidence } \\
\text { limits, } \\
\text { degrees }\end{array}$ \\
\hline $\begin{array}{l}\text { Indirect ophthalmoscopy } \\
\text { Nikon 20 D } \\
\text { Nikon 30 D } \\
\text { Nikon 14 D }\end{array}$ & $\begin{array}{r}15 \\
9 \\
6\end{array}$ & $\begin{array}{l}5 \cdot 5 \\
4 \cdot 8 \\
8\end{array}$ & $\begin{array}{l}0 \cdot 3 \\
0 \cdot 33 \\
0\end{array}$ & $\begin{array}{l}45 \\
34 \\
52\end{array}$ & $\begin{array}{l}\times 3 \cdot 0 \\
\times 2.6 \\
\times 4.2\end{array}$ & $\begin{array}{l}57 \cdot 1 \\
48 \\
42 \cdot 7\end{array}$ & $\begin{array}{l}3 \cdot 8 \\
4 \cdot 1 \\
0\end{array}$ \\
\hline $\begin{array}{l}\text { Slit-lamp examination lenses } \\
150 \mathrm{D} \\
\text { Volk } 90 \mathrm{D} \\
\text { Volk } 78 \mathrm{D} \\
\text { Haag-Streit fundal contact lens } \\
\text { Haag-Streit Hruby lens } \\
\text { Hablin } 2000 \text { ophthalmoscope }\end{array}$ & $\begin{array}{r}21 \\
21 \\
14 \\
13 \\
12 \\
8\end{array}$ & $\begin{array}{l}0.96 \\
1.44 \\
1.79 \\
2 \cdot 08 \\
2.17 \\
1.25 \text { Disc diar }\end{array}$ & $\begin{array}{l}0.09 \\
0.12 \\
0 \cdot 13 \\
0 \cdot 26 \\
0 \cdot 36 \\
\text { meters }\end{array}$ & $\begin{array}{l}8 \\
8 \\
8 \\
6 \cdot 36 \\
5 \cdot 9\end{array}$ & $\begin{array}{r}\times 5 \cdot 2 \\
\times 7 \cdot 7 \\
\times 9 \cdot 6 \\
\times 11 \cdot 2 \\
\times 11 \cdot 7\end{array}$ & $\begin{array}{r}60 \\
37 \\
29 \\
20 \\
17 \\
8\end{array}$ & $\begin{array}{l}6 \cdot 4 \\
3 \cdot 1 \\
2 \cdot 2 \\
3 \cdot 5 \\
2 \cdot 2 \\
-\end{array}$ \\
\hline
\end{tabular}

\section{Discussion}

The +150 dioptre combination lens is used in a similar way to the $+90 \mathrm{D}$ on the slit-lamp. The combination lens is held a little closer to the cornea, $10 \mathrm{~mm}$ compared with the +90 dioptres lens's $15 \mathrm{~mm}$. Though the best images are obtained with a dilated pupil, as is the case with the +90 dioptre lens, it is possible to obtain a satisfactory view with pupils as small as $3 \mathrm{~mm}$ in diameter. The illuminating beam should be at its minimum intensity and set at an angle of $20^{\circ}$ to the objectives, unlike the virtually coaxial beam needed with the $+90 \mathrm{D}$. The beam width can be set to $15 \mathrm{~mm}$ before the image quality deteriorates, compared with $12 \mathrm{~mm}$ with the +90 dioptre lens. This also increases the immediate field of view. The oblique light source also produces a relief to raised areas. The inverted aerial image in front of the lens is viewed in the usual way with the slit-lamp.

The view obtained with the +150 dioptre combination lens is similar to that of the indirect ophthalmoscope, both having a field of view of approximately $60^{\circ}$. However, the aerial image of the +150 dioptre lens is further magnified by the slit-lamp to produce an overall magnification of $\times 5.2$ compared with $\times 3.0$ for the indirect ophthalmoscope. This allows greater detail to be extracted from the image. The magnification can be further altered by the variable slit-lamp optics. The Galilean optics of the latest HaagStreit slit-lamp are particularly suited to this. With the +150 dioptre lens an image similar to that of the indirect ophthalmoscope and the +78 dioptre lens can be obtained by alternating only the slit-lamp magnification.

By decentring the lens, utilising the large prismatic effect of the high power combination lens, and if necessary asking the patient to move his eye, it is possible in a patient with well-dilated eyes to view out to the ora serrata. By working one's way round the eye, in a similar manner to 'spinning' the three-mirror contact lens, the peripheral retina can be examined stereoscopically. Comparing previous fundal photographs with the patient's fundus and drawing a retinal drawing is facilitated by having both patient and observer comfortably seated at the slit-lamp. The good stereopsis and wide field of view allow excellent visualisation and estimations of the size and position of retinal tears and indents after $\vec{\circ}$ retinal detachment surgery. The global view allows the overall pattern of the retinopathy to be $\stackrel{\omega}{\sigma}$ viewed in its entirety instead of having to build $\frac{0}{0}$. up a mental picture while viewing small areas of the fundus. Media opacities disturb the retinal of image to a lesser extent than with the +90 or +78 in dioptre lens, and the +150 dioptre lens is almost as good in this respect as the indirect ophthalmo- 음 scope.

The lower magnification increases the depth of field, enabling excellent visualisation to be obtained of that most difficult of structures to $\vec{\bullet}$ view, the vitreous. This is further enhanced by the oblique light source which is scattered by the vitreous structures and opacities to produce a well defined image.

Biomicroscopy with the +150 dioptre lens produces a retinal image with an overall magnification of $\times 5 \cdot 2$ and with a wide angle of view of $\overrightarrow{\vec{B}}$ $60^{\circ}$. This is comparable to that of the indirect $\exists$ ophthalmoscope being used with a +20 dioptre lens, which produces an angle of view of $57^{\circ}$, but the magnification is lower at $\times 3 \cdot 0$. The +150 응 dioptre lens is particularly useful in screening the eye for pathology. Areas of particular interest can then be viewed easily at higher magnification by changing the examination lens to the +90 dioptre $(\times 7 \cdot 7)$ or +78 dioptre $(\times 9 \cdot 6)$ lens.

1 Helmholtz H. Beschreibung eines Augenspiegels zur $\frac{7}{0}$ Untersuchung der Netzhaut in lebenden Auge. Berlin:

2 Schepens CL. A new ophthalmoscope demonstration. Oo Ophthalmology 1947; 51: 298-301.

3 Hruby K. Spaltlampenmikroskopie des hinteren Augenab- N schnittes ohne Kontaktglas. Klin Monatsble Augenheilkd 1942; 108: 195-200.

4 Schlegel HJ. Eine einfache Weitwinkeloptik zur spaltlampenmikrosckopischen Untersuchung des Augenhintergrundes 0 (Panfundosckop). Doc Ophthalmol 1969; 26: 300-8

5 Eger AR. 90D Volk fundal lens. F Am Optom Assoc 1986; 57: 784-5.

$6 \mathrm{El}$ Bayadi GE. New method of slit-lamp micro- 7 ophthalmoscopy. Brf Ophthalmol 1953; 37: 625-8.

7 Fincham WHA, Freeman MH. Optics. 8th ed. London: Butterworths. 1974: 178-81.

8 Straatsma BR, Foos RY, Spencer LM. The retina-topography and clinical correlations: sypmosium on retina and retinal and clinical correlations: sypmosium

9 Michaels DD. Visual optics and refractions. St Louis: Mosby, 1985: 172-6.

10 Southall JPC. Helmholtz's treatise on physiological optics. New York: Dover, 1962; 1: 350-8.

11 Duane TD, Jaeger EA. Biomedical foundations of ophthal- ڤై mology. Philadelphia: Harper and Row, 1986; 1: chapter 19: 3 . 